NBER WORKING PAPER SERIES

\author{
BORROWING RESTRICTIONS AND WEALTH \\ CONSTRAINTS: IMPLICATIONS FOR \\ AGGREGATE CONSUMPTION
}

Carl E. Walsh

Working Paper No. 1629

NATIONAL BUREAU OF ECONOMIC RESEARCH 1050 Massachusetts Avenue

Cambridge, MA 02138

June 1985

I would like to thank Peter Hartley for helpful comments which improved some of the proofs. In addition, Alan Blinder and seminar participants at the University of North Carolina, the Federal Reserve Bank of Philadelphia, Michigan State University, the University of California, San Diego, and the Federal Reserve Bank of San Francisco provided useful comments on earlier drafts of this paper. The research reported here is part of the NBER's research program in Financial Markets and Monetary Economics. Any opinions expressed are those of the author and not those of the National Bureau of Economic Research. 
NBER. Working Paper \#1629

June 1985

\section{Borrowing Restrictions and wealth \\ Constraints: Implications for \\ Aggregate Consumption}

\section{ABSTRACT}

Recent empirical studies have found that consumption is more sensitive to current income than the life-cycle, permanent income hypothesis would predict. The present paper studies a model in which the fraction of consumers exhibiting excess sensitivity is endogenously determined. The presence of income uncertainty and restrictions on borrowing are shown to generate a distribution of consumption across individuals which is consistent with the recent empirical evidence. The aggregate marginal propensity to consume out of transitory income is directly related to the fraction of constrained consumers and exhibits positive serial correlation in the face of serially uncorrelated income shocks.

Carl E. Walsh

Department of Economics Princeton University Princeton, NJ 08544 (609) 452-4026 
Borrowing Restrictions and Wealth Constraints:

Implications for Aggregate Consumption

Recent empirical research suggests that the observed co-movements of income and consumption are consistent with some fraction of consumption being determined in a manner compatible with the life-cycle, permanent income hypothesis and the remaining fraction being proportional to income. Hall and Mishkin [1982], for example, investigated the consumption of food using panel data on households and concluded that $80 \%$ of consumption obeys the permanent income hypothesis, while $20 \%$ is simply proportional to income.' In a study of aggregate consumption, Hayashi [1982] obtains a point estimate of the share of disposable income going to liquidity constrained households of $17.1 \%$, although he cannot reject the null hypothesis that this fraction is zero. Using consumer expenditures in place of consumption, Hayashi estimates that $96 \%$ of such expenditures are attributable to liquidity constrained households. ${ }^{2}$ Hansen and Singleton [1983] are able to reject the restrictions implied by the first order Euler equations obtained from a standard specification of a life-cycle consumption choice problem, and Zeldes [1984] presents evidence to suggest that the violation of these restrictions is due to the presence of liquidity constrained households. In addition, Ferson and Merrick [1985] report that the evidence against the Euler restrictions is strongest in periods of aggregate economic recession.

If aggregate consumption is the sum of consumption by liquidity constrained households and consumption by unconstrained households, then the aggregate marginal propensity to consume out of transitory income 
should be an average of one (for the constrained individuals) and a small positive number (for the unconstrained) with weights dependent on the fraction of all consumers who actually are constrained. It is unfortunate then that there currently appears to be no model which explains the determinants of the percentage of households which fall into each class. For example, previous studies of optimal consumption in the presence of capital market imperfections (e.g. Flemming [1973], Heller and Starr [1979] $)^{3}$ have not explicitly modeled the probability that a given individual will be constrained nor considered the determinants of the aggregate fraction of consumers who are constrained. This paper attempts to at least partially fill this gap. The approach adopted is to study the distribution of assets across households when there are borrowing restrictions and income uncertainty. It is shown that each period a positive fraction of the population of consumers will find themselves wealth constrained, while the remaining fraction will not be so constrained and will appear to behave according to the life-cycle, permanent income hypothesis. The aggregate marginal propensity to consume out of transitory income is shown to be directly related to the fraction of all consumers who are wealth constrained, and this fraction is shown to exhibit positive serial correlation in response to serially uncorrelated income disturbances.

To constrast sharply with the perfect capital market assumption of the standard permanent income formulation, the model developed here assumes that consumers cannot borrow against any future income receipts. Current consumption is therefore limited by current resources. Excess sensitivity of aggregate consumption then arises because some consumers 
find their current wealth to be insufficient to finance their desired level of consumption. The evidence from the recent Survey of Consumer Finances [1984] suggests that a significant fraction of American families have levels of financial asset holdings which, in the absence of the ability to borrow against future labor income, would be insufficient to insulate consumption from even moderate declines in current income. For example, in $1983,12 \%$ of all families, and $34 \%$ of those with incomes less than $\$ 10,000$, reported no financial assets. Almost $40 \%$ of all families reported firiancial asset holdings of less than $\$ 1000.4$ It seems quite plausible to expect that consumption for a nonnegligible fraction of the population would be forced to move quite closely with fluctuations in current income.

The basic choice problem facing the individual consumer is similar to that analyzed by Sibley [1975], Schechtman [1976], Schechtman and Escudero [1977], and Bewley [1977], and their results will be drawn upon. The focus of these authors has been the optimal consumption plan of an individual consumer facing income uncertainty. ${ }^{5}$ In the formulations of Schechtman [1976] and Bewley [1977], for example, no borrowing is allowed. They both show, however, that in the limit as the individual's planning horizon goes to infinity and the subjective rate of time preference goes to zero, the consumer holds enough wealth to completely self-insure against any income fluctuations. In this case, the borrowing restriction is never binding. As will be discussed in section $I$, this result would seem to be inconsistent with the empirical evidence. In addition, none of these authors consider the aggregate implications of borrowing restrictions. 
The present paper, like those of Lucas [1980] and Clarida [1984], is directed towards the aggregate implications of the consumer's choice problem. Both Lucas [1980] and Clarida [1984] find that the distribution function of money balances (the single asset in their models) has a mass point at the minimum value necessary to finance consumption. By providing a new interpretation of this characteristic of the distribution of asset holdings, the present paper shows how the empirical results found by Hall and Mishkin [1982]; Hayashi [1982] and Flavin [1984] might arise. The contribution of the present paper, besides providing a reinterpretation of earlier results which is consistent with recent empirical findings, is to examine the determinants of the fraction of consumers who are wealth constrained. In addition, by assuming that transitory income fluctuations have both an individual specific and a common (business cycle) component, it is shown how the aggregate excess sensitivity of consumption to transitory income is generated as a function of the endogenously determined fraction of consumers who are constrained.

The consumer's basic choice problem is discussed in the next section, and the optimal consumption plan of the individual is studied. Section II shows that the distribution of wealth across individuals converges to a unique stationary distribution when income shocks are individual specific and aggregate transitory income is zero. This distribution is used to derive the fraction of consumers who will become wealth constrained each period. Optimal consumption and the distribution of wealth with a wealth in advance requirement are compared, in section III, to the outcomes which would arise if borrowing were allowed. Aggregate consumption in the presence of an economy-wide component to 
transitory income is examined in section IV. Section V contains the paper's conclusions.

I. The Individual Consumer

This section sets up the problem facing each consumer and shows that there is a critical value of spendable resources such that consumers with assets less than this value are wealth constrained. The consumer's choice problem is fairly standard (see Sibley [1975], Yaari [1976], Schechtman [1976], Bewley [1977], Schechtman and Escudero [1977], Lucas [1980], Clarida [1984]). Consequently, the proofs of some of the propositions are omitted. The focus of the present analysis, unlike that of earlier work, is on deriving the probability an individual will find the restriction against borrowing to be binding.

The economy studied consists of a large number of identical, infinitely lived individuals. Only one asset, assumed for simplicity to be noninterest bearing, is available to wealth holders, and current consumption must be financed by either beginning of period holdings of this asset or current income receipts. The asset can be thought of as nondepreciating storage, although Bewley [1980], Lucas [1980] and Clarida [1984] prefer to call it money. Individuals have preferences given by

$$
E\left\{\Sigma_{0}^{\infty} \beta^{t} u\left(c_{t}\right)\right\} \text {. }
$$

The function $u()$ is taken to be bounded, twice continously differentiable, strictly increasing, strictly concave in $c$, with $\lim _{c \rightarrow a} u_{c}(c)=\infty$, and $\lim _{c \rightarrow \infty} u_{c}(c)=0$. The discount rate $B$ is restricted to lie between 0 and 1 . 
At the start of each period, the ith individual receives an endowment equal to $y+\varepsilon_{i}+u$, where $y$ is a nonstochastic income payment (permanent income), and $\varepsilon_{i}$ and $u$ are independently distributed, serially uncorrelated random variables with zero means. Both $\varepsilon$ and $\mathrm{u}$ represent transitory income, with $\varepsilon_{i}$ equalling an idiosyncratic shock while u is a shock common to all individuals. Let the cumulative distribution functions of $\varepsilon_{i}$ and $u$ be given by $S($ ) and $G()$, respectively. While the realizations of the idiosyncratic income shock will differ across individuals, the distribution from which they are drawn is common to all consumers. The support of $\varepsilon$ is taken to be the closed interval $[\underline{\varepsilon}, \bar{\varepsilon}]$, while that of $u$ is the closed interval $[\underline{u}, \bar{u}]$. In addition, it is as sumed that $y+\underline{\varepsilon}+\underline{u}>0$, so that each individual's endowment is strictly positive for all possible realizations of transitory income.

Because $\varepsilon$ and u are i.i.d., the consumer cares only about their sum. This would not be the case, for example, if either were Markov with transition probabilities dependent on the current realizations. Even though each individual's consumption depends only on $\varepsilon+u$, the distinction between individual specific and common transitory income will be needed in order to consider how aggregate consumption responds to aggregate income fluctuations. Define $\phi=\varepsilon+u$. Then the support of $\phi$ is $[\underline{\varepsilon}+\underline{u}, \bar{\varepsilon}+\bar{u}]$, and

$$
\operatorname{Prob}\left[\phi \leq \phi^{\prime}\right]=\int_{\underline{u}}^{\bar{u}} S\left(\phi^{\prime}-u\right) d G(u)=F\left(\phi^{\prime}\right)
$$

If $w_{t}$ is the individual's wealth at the start of period $t$, prior to the receipt of the current income endowment, the borrowing restriction can be written as 


$$
c_{t} \leq w_{t}+y+\phi_{t}=A_{t}
$$

where $A_{t}$ denotes currently available spendable resources. The budget constraint faced by the consumer takes the form

$$
A_{t+1}=A_{t}-c_{t}+y+\phi_{t+1}
$$

If the individual's asset holdings, $A$, are identified with money, equation (2) is a cash-in-advance constraint. The practical implication of (2) is that current income can be spent in the current period but future income cannot. Each individual enters the current period with a level of wealth determined by past income realizations and spending flows. The individual then observes $\phi$, the current shock to income. A level of current consumption is then chosen. Finally, the consumer carries over into the next period $A-c$.

Let $\phi^{\prime}$ denote next period's income shock, and define $v(A)$ as the optimal value function for a consumer who has initial spendable resources A and acts to maximize (1) subject to (2) and (3). The following proposition is proven by Lucas [1980, Prop. 1, p. 136]:

Proposition 1: There exists a unique, bounded, continuous function $v(A)$, strictly concave in $A$, such that

$$
\mathrm{v}(\mathrm{A})=\max _{c \leq A}\left\{\mathrm{u}(\mathrm{c})+\beta \int \mathrm{v}\left(A-c+y+\phi^{\prime}\right) \mathrm{dF}\left(\phi^{\prime}\right)\right\}
$$


Letting $\mu$ and $\lambda$ denote the Lagrangian multiplers associated with the constraints (2) and (3) respectively, the first order conditions for utility maximization, together with the envelope theorem, imply

$$
\begin{aligned}
\mathrm{v}_{A}(A) & =\mu+\lambda(=\lambda \text { if } c<A) \\
\mathrm{u}_{c}(c) & =\mu+\lambda(=\lambda \text { if } c<A) \\
B E v_{A}\left(A^{\prime}\right) & =\lambda
\end{aligned}
$$

together with (2) and (3). The individual will be described as wealth constrained if $\mu>0$ in which case $c=A$. From (6) and (7), $u_{c}(c)>$ $B E v_{A}\left(A^{\prime}\right)$ for a constrained consumer. This implies that the consumer would experience a rise in total utility if he/she were able to exchange a unit of future wealth for a unit of current consumption. The borrowing prohibition prevents the consumer from doing this. Equations (5) (7) imply $\beta E u_{c}\left(c^{i}\right) / u_{c}(c) \leq 1$, with strict equality holding for unconstrained consumers. Hansen and Singleton [1983] find, using data on aggregate U.S. consumption, that they can reject the null hypothesis that $\beta E u_{c}=u_{c} \cdot{ }^{6}$ With borrowing restrictions, $\beta E u_{c}<u_{c}$ for constrained consumers, and the presence of such constrained individuals may explain the results Hansen and Singleton obtain. Such an interpretation is supported by the empirical work of Zeldes [1984].

In order for the presence of borrowing restrictions to explain these empirical results, it is necessary to verify that there will be some consumers for whom (2) actually is a binding constraint. Otherwise, $B u_{c}\left(c^{\prime}\right)=u_{c}(c)$ for all consumers, and Zeldes' [1984] results could not be captured in the present model. For example, Schechtman [1976] and 
Bewley [1977] both show, using a very similar framework, that in a finite horizon model the stationary value of A approaches $\infty$ as both the horizon and $1 /(1-\beta)$ go to $\infty$. Each consumer completely self-insures against transitory income fluctuations, and, in the stationary state, (2) is never binding for any consumer.

It will be useful to have an explicit representation of optimal consumption behavior by the individual consumer.

Proposition 2: There exists a unique, continuous function $c(A)$ such that $c_{A}>0$, and

$$
v(A)=u(c(A))+\beta J v\left(A-c(A)+y+\phi^{\prime}\right) d F\left(\phi^{\prime}\right)
$$

Proof: See Lucas [14, Prop. 2, p. 137] for a proof of the uniqueness and continuity parts of the proposition. From (5) and $(6), v_{A}(A)=$ $u_{c}(c(A))$ for all $A$. The strict concavity of $v$ implies that $c(A)$ is strictly increasing in A.

Each individual enters the period with some predetermined level of $w$. Each individual also knows the value of permanent income, y. For some realizations of $\phi$, current available resources, $A=w+y+\phi$, may be insufficient to allow the desired level of consumption to be achieved without violating the constraint (2). The rest of this section will demonstrate that there exists a $\phi^{*}$ such that for all $\phi<\phi^{*}$ the individual is constrained. Then, the probability of being constrained is just 
$F\left(\phi^{*}\right)$. The basic intuition behind this result is straightforward. Suppose the transitory income realization equals $\phi^{\prime \prime}<0$. Spendable resources, A, fall below their expected value by the full amount $\phi^{\prime \prime}$. However, desired consumption should decline less since $\phi$ is purely transitory income. A lower realization of transitory income reduces spendable resources more than it reduces desired consumption, and A - c falls with $\phi$. For some sufficiently low realization of $\phi$, say $\phi *$, the optimal c will exactly equal A.

To show this more formally, define $A^{*}$ as the solution to

$$
u_{C}\left(A^{*}\right)=\beta E v_{A}\left(y+\phi^{\prime}\right) \text {. }
$$

Given the assumed properties of the utility function and the distribution of $\phi$, such an $A^{*}$ exists, since the right hand side of (8) is finite and independent of $A$ while the left hand side is monotonic in $A, \lim _{\boldsymbol{A}} \rightarrow$ $u_{c}(A)=\infty$, and $\lim _{A \rightarrow \infty} u_{C}(A)=0$. Then, from (5) - (7), if $A=A^{*}$, the optimal value of current consumption is $c=A$. If $A<A *$, the constraint $c \leq$ A will become binding:

Proposition 3: The borrowing constraint is binding if and only if $A$ $<A \div$.

Proof: Write the right side of ( 8 ) as $B V$ where $V$ is independent of A. Suppose for some $A>A *$ the individual is constrained. Then $c=A$, $\mu \geq 0$, and $u_{c}(A) \geq B V$. But $u_{c}(A)<u_{c}(A *)=B V$ if $A>A *$ which is a contradiction. Now suppose $A<A^{*}$. Then $c(A) \leq A<A *$ and

$$
\begin{aligned}
u_{c}(c(A)) \geq u_{c}(A) & >u_{C}(A *) \\
& =B V=B E v_{A}\left(y+\phi^{\prime}\right)
\end{aligned}
$$




$$
\geq B E v_{A}\left(A-c(A)+y+\phi^{\prime}\right)
$$

since $A-c(A) \geq 0$ and $v_{A}$ is nonincreasing But from (6) and (7) this implies $\mu>0$. Finally, for $A=A^{*}, c(A)=A$ and $\mu=0$, so the borrowing constraint is not strictly binding.

Since $A=w+y+\phi$, the following is immediate:

Proposition 4: For all $w>w^{*}=A^{*}-y-\phi, \mu=0$.

Any individual with beginning of period wealth greater than $w^{\frac{1}{*}}$ will not be constrained, since even with the lowest transitory income realization, the individual has enough spendable resources to finance desired consumption.

Similarly, define $w^{* *}=A^{*}-y-\bar{\phi}$.

Proposition 5: For all $w<w^{\circ}$ : $\mu>0$.

Individuals with $w<w^{*}$ will be constrained even with the largest possible realization of income, since, for them, $w+y+\bar{\phi}<A *$.

For all $w$, $w^{* *}<w<w^{*}$, we can define

$$
\phi *=\phi *\left(w, A^{*}\right)=A *-w-y
$$

If an individual with wealth $\mathrm{w}^{7}$ receives an income shock $\phi<\phi^{*}\left(w, A^{*}\right)$, then $A<A^{*}$, and the individual will be constrained. $\phi^{*}$ gives the critical value of transitory income, as a function of beginning of period 
wealth and $A^{*}$, such that the consumer finds the borrowing restriction binding if and only if $\phi<\phi^{*}$.

Proposition 6: The probability an individual with beginning of period wealth w will be constrained is $F\left(\phi^{*}\right)$.

In Figure 1, the function $\phi *\left(w, A^{*}\right)$ is illustrated, together with the associated probability of being constrained. In the right hand panel of the figure, $\phi^{*}$, which is linear in $w$, declines from the value $\bar{\phi}$ when $w \leq$ $w^{*} \div$ (Proposition 5) to $\Phi$ when $w \geq w^{\text {th }}$ (Proposition 4). If an individual has wealth equal to $\omega_{1}$, for example, he/she will be constrained if $\phi<$ $\phi_{1}$. The left hand panel, which plots the cumulative distribution function of $\phi$, shows that the probability of being constrainted is $F_{1}$. This probability is nonincreasing in $w$.

Equation (9) shows that an increase in $A^{*}$ increases $\phi *$ for each $w$ and shifts the $\phi *$ locus in Figure 1 to the right. The shift is a parallel one as $w^{* *}$ and $w^{*}$ both increase by the same amount as the rise in $A^{*}$. Thus, the probability of being constrained in nondecreasing in $A *$.

As of yet, it has not been shown that any consumers will have levels of wealth less than $w^{*}$. It could be the case that all consumers accumulate enough wealth to insure that the borrowing constraint never binds. For all consumers, the probability of being constrained would then be zero. For example, it has already been mentioned that in a similar model with no discounting of future utility $(\beta=1)$, Schechtman [1976] shows that $A *$ converges almost surely to $\infty$. A then can never fall below $A^{*}$, and (2) is never binding. 


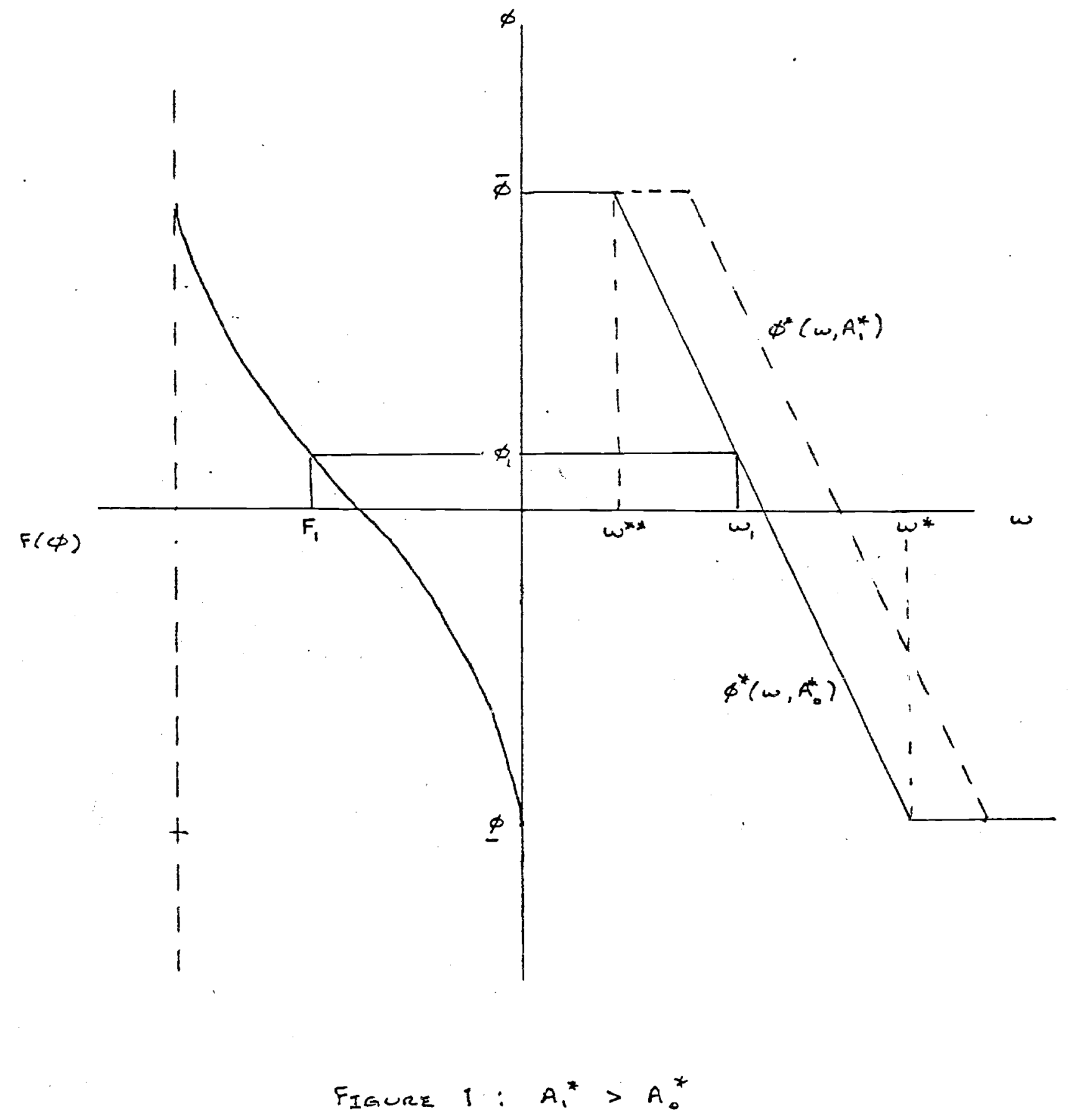


Alternatively, if $A^{*}=0$, the constraint never binds since $A$ cannot fall below zero. To see when $A^{*}$ might equal zero, rewrite (8), making use of (5) and (6), as

$$
\begin{aligned}
u_{c}\left(A^{*}\right)= & \beta E u_{c}\left(c\left(y+\phi^{\prime}\right)\right) \\
= & \beta \int u_{c}\left(c\left(y+\phi^{\prime}\right)\right) d F(\phi) \\
& <\beta u_{c}(y+\phi)<u_{c}(y+\phi) .
\end{aligned}
$$

From $\left(8^{\prime}\right)$ it follows immediately that $A^{*}>y+\phi>0$. However, this result depended on the assumption that $u_{c}(y+\phi)<\infty$. Suppose instead that the endowment can equal zero with positive probability. Then, since $u_{c}(0)=\infty$, the consumer will insure that spendable resources exceed zero by always consuming strictly less than $A$ if there is any probability of the endowment in the next period equalling zero. More specifically, if $f()$ is the density function of $\phi$,

Proposition 7: If $\lim _{\phi \rightarrow \underline{\psi}^{.}} u_{c}(y+\phi) f(\phi)=\infty$, then $A^{*}=0$.

Proof: Under the stated conditions, $\mathrm{Eu}_{c}\left(y+\phi^{\prime}\right)=\infty$, so that, from $\left(g^{\prime}\right), u_{c}\left(A^{*}\right)=\infty$. Hence, $A^{*} *=0$.

Proposition 8: Given an individual's current spendable resources, the probability of being constrained is nondecreasing in permanent income. 
Proof: From (8) and Proposition 1, $\beta E V_{A}\left(y+\phi^{\prime}\right)=B V$ is decreasing in y. Hence, $A^{*}$ is increasing in $y$. From (9), $\phi^{*}$, is nondecreasing in $A^{*}$. Since $F()$ is a nondecreasing function, $F\left(\phi^{*}\right)$ is nondecreasing in $y$.

A rise in future permanent income leads to a rise in current desired consumption. With current spendable resources fixed, this rise in desired consumption tends to increase the probability that the constraint (2) will be binding. The probability of becoming constrained in the future is also affected by decisions about consumption in the current period. For consumers who are not constrained in the current period, a decision to increase current consumption will increase the probability of becoming constrained in the next period. This probability is given by the probability that $\phi^{\prime} \leq A^{*}-w^{*}-y=A^{*}-(A-c)-y$. Given $A$ and $y$, this is nondecreasing in $c$ :

As was shown previously; constrained consumers will violate the Euler equations commonly assumed to characterize optimal consumption choice. Equations (5) - (7) can be rearranged to yield

$$
u_{c}\left(c_{t+1}\right)=\beta^{-1} u_{c}\left(c_{t}\right)+\xi_{t+1}
$$

where $\xi_{t+1}=\left[u_{c}\left(c_{t+1}\right)-E_{t} u_{c}\left(c_{t+1}\right)\right]-B^{-1} \mu_{t}$. Standard Euler tests of optimal consumption choice test the hypothesis that $E_{t} \xi_{t+1} X_{t}=0$, where $X_{t}$ is a vector of variables observable at time $t$ or earlier. Kotlikoff and Pakas [1984] provide a general discussion of the implications of the standard form of the first order Euler equation. These tests have attempted to exploit the implication of efficient linear predictors that 
$\xi_{t+1}$ should be unforecastable on the basis of any information known at time t. In particular, $E\left(\xi_{t+1} / \xi_{t}\right)=0$, so that $\xi$ should be serially uncorrelated. This result no longer holds if any consumers are wealth constrained. From $(10), E_{t}\left(\xi_{t+1}\right)=-\beta^{-1} \mu_{t} \leq 0$, with strict inequality for constrained consumers. Such a result in cross-sectional data is consistent with Zeldes [1984]. Since $\mu_{t}$ is a decreasing function of current transitory income, ${ }^{8} E\left(\xi_{t+1} / \phi_{t}\right)>0$ for constrained consumers. When transitory income is added to a regression equation based on (10), it should have a positive coefficient. This is what Flavin [1984] finds with aggregate data.

In addition, $\mu_{t}$ will itself be positively serially correlated since a consumer constrained during period $t$ carries no assets into period $t+1$ and thereby increases the probability that $\mu_{t+1}$ will be positive. Suppose $\gamma_{i t+1}$ is the probability consumer $i$ will be constrained during period $t+1: \gamma_{i t+1}=F\left(\phi *\left(w_{i t+1}, A *\right)\right)$. If $\mu_{i t}>0$, then $w_{i t+1}=0$, and $\gamma_{i t+1}=F(\phi *(0, A *))>F(\phi *(w, A *))$ for all $w>0$. Being constrained at time $t$ increases the probability of being constrained at time $t+1$. This raises the expected value of both $\mu_{t+1}$ and $\xi_{t+2}$. This serial correlation in the probability of being constrained arises even though the underlying income shocks are i.i.d.

II. The Distribution of Assets With No Common Shock

By itself, knowledge of the probability an individual consumer will become constrained, as a function of the consumer's wealth, is of limited usefulness for understanding aggregate consumption. This is because 
the fraction of all consumers who find the borrowing restriction to be binding will depend on the distribution of wealth across the population of consumers. In this section, the stationary state fraction of consumers who will actually be constrained is derived for the case in which there is no aggregate uncertainty. All income shocks are taken to be idiosyncratic, with the common shock, u, identically zero. The case in which u has a nondegenerate distribution is considered in section IV.

At the beginning of each period, there will be some distribution of $A$ across individuals. Let this distribution be denoted by $\Psi(A)$. That is, $\Psi(A)$ equals the fraction of the total population of consumers with beginning of period wealth plus current income less than or equal to $A$. The subsequent consumption decisions and realizations for each individual of transitory income result in a new distribution of wealth plus income for the following period. It will be shown that there exists a stationary distribution to which any initial distribution of A converges.

From the budget constraint ( $\left.3^{\prime}\right)$ and the optimal consumption function $c(A)$,

$$
\begin{aligned}
\operatorname{Prob}\left[A_{t+1} \leq A^{\prime} / A_{t}=A\right] & =\operatorname{Prob}\left[\varepsilon \leq A^{\prime}-A-y+c(A)\right] \\
& =S\left(A^{\prime}-A-y+c(A)\right)
\end{aligned}
$$

The unconditional probability that $A_{t+1} \leq A^{\prime}$ is then given by $\int S\left(A^{\prime}-A-y+c(A)\right) d \Psi(A)$ if $\Psi(A)$ is the initial distribution of $A$. Define the operator $\mathrm{P}$ such that

$$
P \Psi\left(A^{\prime}\right)=\int S\left(A^{\prime}-A-y+c(A)\right) d \Psi(A)
$$


Proposition 9: There exists a unique c.d.f. $\Psi:$ such that $P \Psi \div=\Psi \div$. The ergodic set of $A$ is $[\underline{A}, \bar{A}]$, where $\underline{A}$ and $\bar{A}$ are defined as the solutions to $c(\underline{A})=y+\underline{\phi}$, and $c(\bar{A})=y+\bar{\phi}$. For any initial c.d.f. $\Psi, \lim _{n \rightarrow \infty} \mathrm{P}^{\mathrm{n}_{\Psi}}$ $=\Psi \div$.

Proof: The proof, omitted here, is a straightforward application of the results in appendix 2 of Danthine and Donaldson [6].

Since $A=w+y+\phi$, it follows immediately that $w$ has a unique distribution function with ergodic set $[\underline{w}, \bar{w}]$, where $\underline{\underline{w}}=\underline{A}-\mathrm{y}-\underline{\phi}$ and $\overline{\mathrm{w}}=\overline{\mathrm{A}}$ - $y-\bar{\phi}$. Let $\Omega(w)$ denote the c.d.f. of $w$. The intervals $[\underline{w}, \bar{w}]$ and $[\underline{A}, \bar{A}]$ are illustrated in Figure 2 .

It is now possible to prove that in the stationary equilibrium some positive fraction of all consumers will in fact be constrained each period. Define

$$
\Gamma=\int S(\phi *(w, A *)) \mathrm{d} \Omega(w)=\Psi(A \div)
$$

$\Gamma$ is the expected fraction of the population of consumers who will experience a binding wealth constraint. With a continuum of consumers, $\Gamma$ is also the fraction who will actually be constrained.

Proposition 10: $\Gamma>0$.

Proof: Since $S \geq 0, \Gamma$ is the expectation of a nonegative function of w. Hence, $\Gamma>0$ as long as some positive probability is assigned by $\Omega$ to values of $w$ for which $S\left(\phi^{*}\left(w, A^{*}\right)\right)>0$. This will be the case as long 


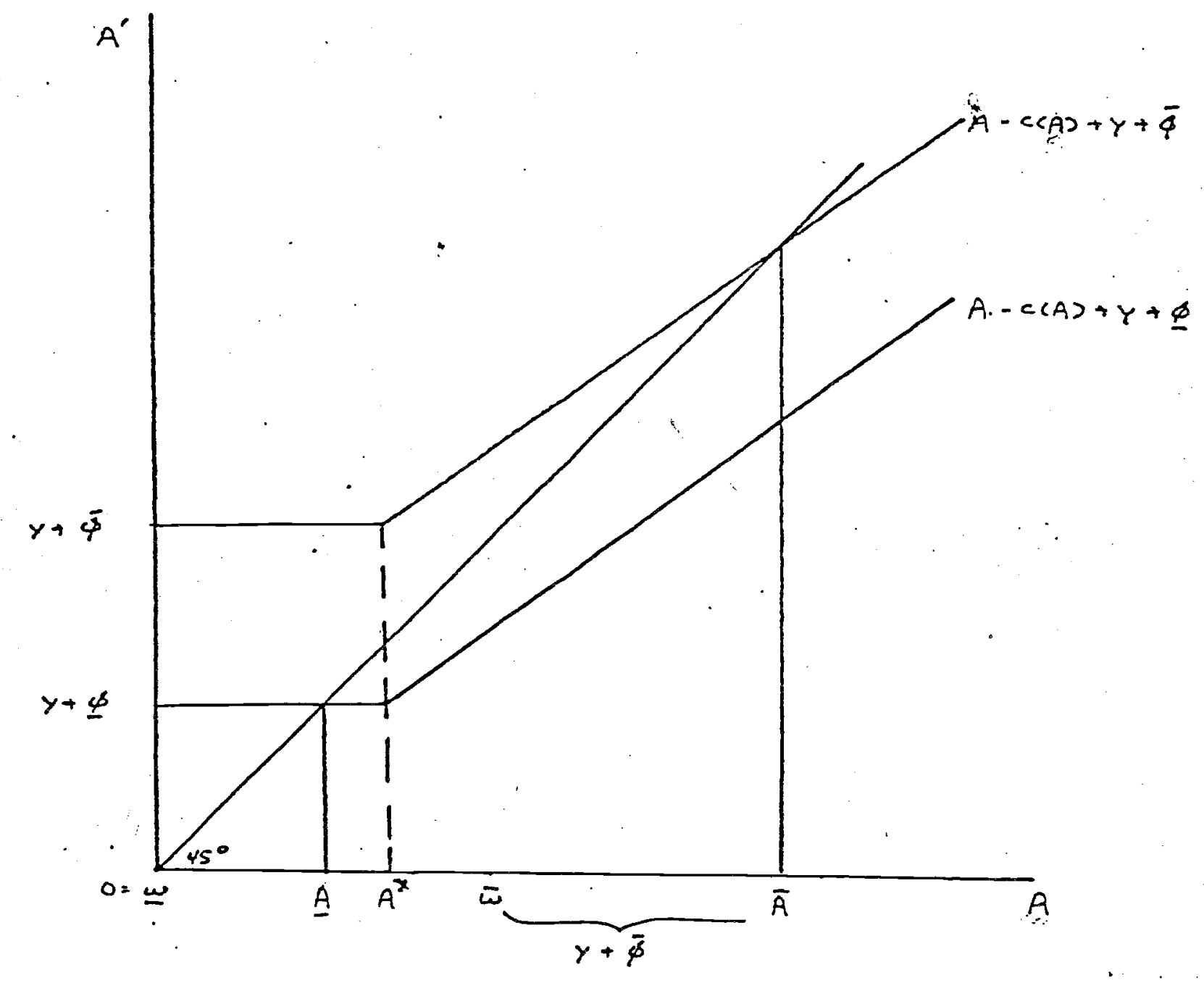

Figure 2 


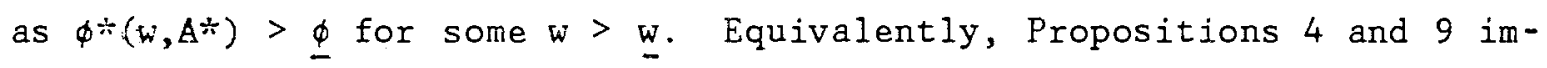
ply $\Gamma>0$ if and only if there exists a $w$ in the interval ( $w$, $w$ ). This requires that $w^{*}>\underline{w}$. But $w^{*}=A^{*}-y-\Phi>\underline{W}=\underline{A}-\mathrm{y}-\underline{\phi}$ if and only if $A * \underline{A}$. Suppose $A * \underline{A}$. By the definition of $\underline{A}, c(\underline{A})=y+\underline{\phi}$, and $\underline{A}$ - $c(A)+y+\phi \geq \underline{A}$ for all $\phi$. Hence, from (5) - (7) and Proposition 1,

$$
\begin{aligned}
v_{A}(\underline{A})=u_{C}(c(A)) & =\beta E v_{A}(\underline{A}-c(\underline{A})+y+\phi) \\
\leq & \beta v_{A}(A)
\end{aligned}
$$

which is a contradiction since $0<\beta<1$.

This is just a standard inventory result - it is never optimal to reduce the probability of stocking out to zero. In the present context, it implies that a positive fraction of all consumers will find the borrowing restriction binding. The remaining fraction, $1-\Gamma$, will be unconstrained.

The result that $\Gamma>0$ is an immediate consequence of the facts that $A^{*}>0$ and $\underline{A}<\infty$. If $A^{*}$ were equal to zero, no consumer would ever be constrained, while if $\underline{A}=\infty$, all consumers completely self insure against fluctuations in income. As Figure 2 shows, the assumption that $y+\underline{\phi}>0$ insures that $A *>0$. The consumer is never faced with a binding wealth constraint in the stationary state if $\underline{A}=\infty$, as in the models of Schechtman [1976] and Bewley [1977]. However, $A=\infty$ holds only in the limit as $\beta \rightarrow 1$ (See, for example, Schechtman [1976, p. 240].), a case ruled out in the present analysis. The role of the assumption that consumers discount future expected utility $(\beta<1)$ is apparent in the proof of Proposition 10. 


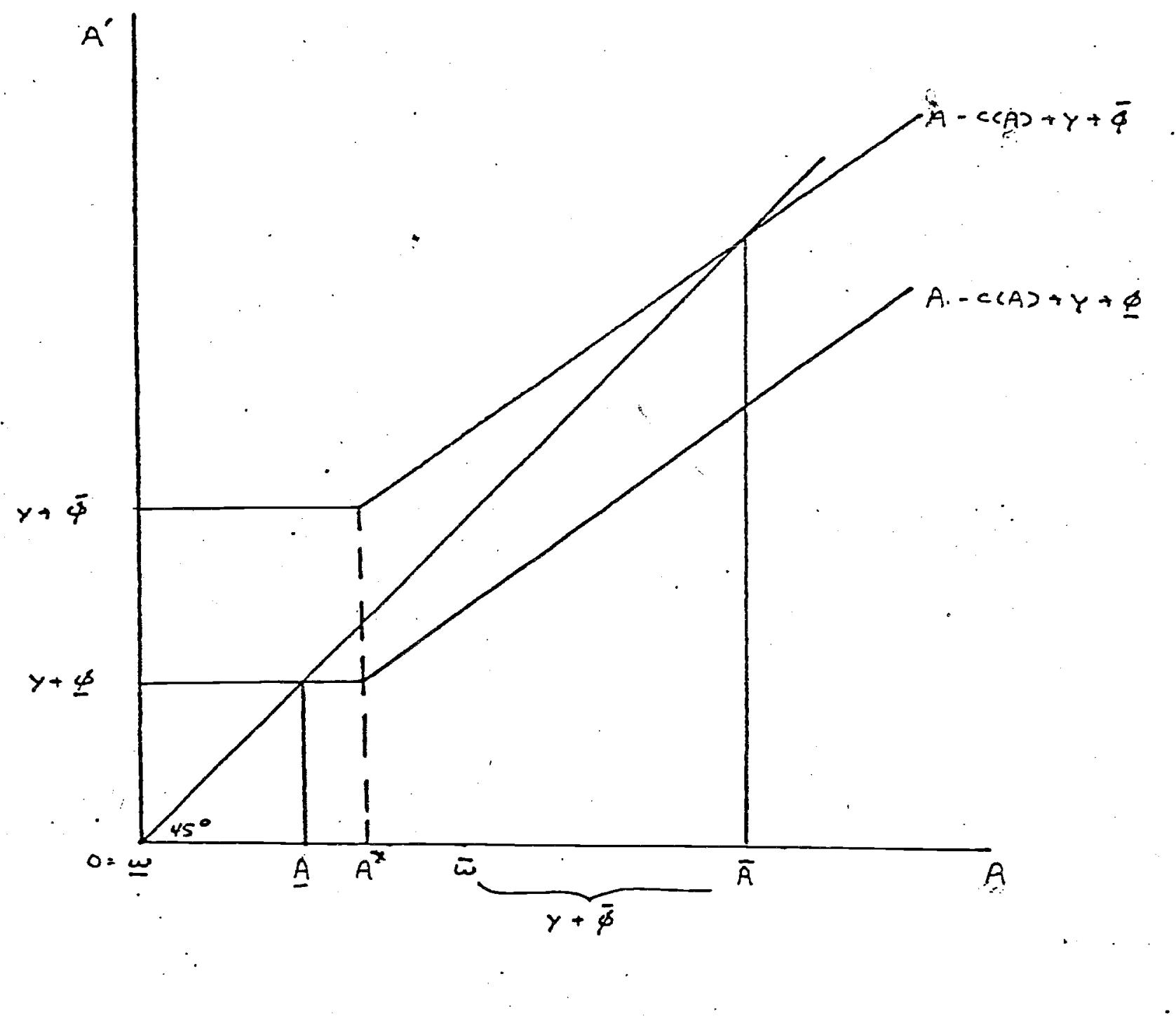

Figure? 
as $\phi^{*}\left(w, A^{*}\right)>\Phi$ for some $w>\underline{w}$. Equivalently, Propositions 4 and 9 imply $\Gamma>0$ if and only if there exists a $w$ in the interval $\left(\underline{w}, w^{*}\right)$. This requires that $\omega^{*}>\underline{w}$. But $\omega^{*}=A^{*}-y-\underline{\phi}>\underline{w}=\underline{A}-y-\underline{\phi}$ if and only if $A *>\underline{A}$. Suppose $A * \leq \underline{A}$. By the definition of $\underline{A}, c(\underline{A})=y+\underline{\phi}$, and $\underline{A}$ $-c($ A) $+y+\phi \geq \underline{A}$ for all $\phi$. Hence, from (5) - (7) and Proposition 1,

$$
\begin{aligned}
v_{A}(A)=u_{c}(c(A)) & =B E v_{A}(\underline{A}-c(\underline{A})+y+\phi) \\
\leq & B v_{A}(A)
\end{aligned}
$$

which is a contradiction since $0<\beta<1$.

This is just a standard inventory result - it is never optimal to reduce the probability of stocking out to zero. In the present context, it implies that a positive fraction of all consumers will find the borrowing restriction binding. The remaining fraction, $1-\Gamma$, will be unconstrained.

The result that $\Gamma>0$ is an immediate consequence of the facts that $A^{*}>0$ and $\underline{A}<\infty$. If $A^{*}$ were equal to zero, no consumer would ever be constrained, while if $\underline{A}=\infty$, all consumers completely self insure against fluctuations in income. As Figure 2 shows, the assumption that $y+\Phi>0$ insures that $A *>0$. The consumer is never faced with a binding wealth constraint in the stationary state if $\underline{A}=\infty$, as in the models of Schechtman [1976] and Bewley [1977]. However, $\underline{A}=\infty$ holds only in the limit as $\beta \rightarrow 1$ (See, for example, Schechtman [1976, p. 240].), a case ruled out in the present analysis. The role of the assumption that consumers discount future expected utility $(B<1)$ is apparent in the proof of Proposition 10. 
Equation (13) suggests that changes in any of the factors exogenous to the model can potentially affect the fraction of constrained consumers in either of two ways. First, for a given distribution of A across the population of consumers, anything which affects $A *$ will cause $I$ to change. Second, if the stationary state distribution of A is affected, I will also change. For example, for a given $\Psi($ ), Proposition 8 implies that a rise in $y$ will increase $A *$, by increasing desired current consumption, and cause $\Gamma$ to rise. However, a rise in real permanent income will also shift the distribution of wealth to the right. In the new steady state, fewer consumers will have levels of spendable resources less than or equal to any given value of $A$. This fall in the fraction of consumers with low A's will tend to reduce $\Gamma$. The net effect depends on the relative magnitudes of these two opposing influences. In the special case of constant relative risk aversion and income shocks proportional to permanent income, the steady state fraction of consumers who become constrained is independent of the level of permanent income:

Proposition 11: If $u(c)=c^{1-b} /(1-b), b \geq 0$, and $\phi=y \xi$ where $\xi$ has mean zero and c.d.f. $G()$ defined on $[\underline{\xi}, \bar{\xi}], \underline{\xi}>-1$, then the stationary state value of $\Gamma$ is independent of $y$.

Proof: We first show that the distribution of $z=A / y$ is homogeneous of degree zero in $y$ and that $A *(y)$ is homogeneous of degree one in $y$. It then follows that $\Gamma(y)=\operatorname{Prob}\left(z \leq A^{*}(y) / y\right)=\operatorname{Prob}\left(z \leq A^{*}(\lambda y) / \lambda y\right)=$ $\Gamma(\lambda y)$ for any $\lambda>0$. Write $c(A, y)$ to make explicit the dependence of consumption on $y$. Given the assumed form of the utility function, $c(\lambda A, \lambda y)=\lambda c(A, y)$. Let $H_{y}(z)$ denote the c.d.f. of $z$ for given $y$. 


$$
\begin{aligned}
\operatorname{Prob}\left[\left(A_{t+1} / y\right) \leq\left(A^{\prime} / y\right) /\left(A_{t} / y\right)=(A / y)\right] & =\operatorname{Prob}\left[\varepsilon^{\prime} \leq\left(A^{\prime}-A+c(A, y)\right) / y\right] \\
& =G\left[\left(A^{\prime}-A+c(A, y)\right) / y\right] .
\end{aligned}
$$

Define the operator $T H=\int G\left[\left(A^{\prime}-A+c(A, y)\right) / y\right] d H$ for c.d.f. H. In the steady state, $\mathrm{TH}_{\mathrm{y}}=\mathrm{H}_{\mathrm{y}}$. Since $\mathrm{G}\left[\left(\mathrm{A}^{\prime}-\mathrm{A}+\mathrm{c}(\mathrm{A}, \mathrm{y})\right) / \mathrm{y}\right]=$ $G\left[\left(\lambda A^{\prime}-\lambda A+c(\lambda A, \lambda y)\right) / \lambda y\right], T H_{\lambda y}=H_{\lambda y}$ also. Hence, $H_{y}=T H_{y}=T^{2} H_{y}=\ldots$ $=\lim _{i \rightarrow \infty} T^{i_{H}}=H_{\lambda Y}$. From (5), (6), and (9),

$$
A^{*}(y)^{-b}=B E_{A}\left(y+\phi^{\prime}\right)=\beta E c\left(y\left(1+\varepsilon^{\prime}\right), y\right)^{-b},
$$

or $A^{*}(y)=\left[\beta E c\left(y\left(1+\varepsilon^{\prime}\right), y\right)^{-b}\right]^{-1 / b}$. It follows that

$$
A^{*}(\lambda y)=\left[\beta E c\left(\lambda y\left(1+\varepsilon^{\prime}\right), \lambda y\right)^{-b}\right]^{-1 / b}=\lambda A *(y) \text {. }
$$

Therefore,

$$
A *(\lambda y) / \lambda y=\lambda A *(y) / \lambda y=A *(y) / y,
$$

and

$$
\Gamma(y)=H_{y}\left(A^{*}(y) / y\right)=H_{\lambda y}\left(A^{*}(\lambda y) / \lambda y\right)=\Gamma(\lambda y)
$$

The fraction of consumers who become constrained each period will depend on the utility discount factor $\beta$. A rise in the subjective rate of discount ( a fall in $\beta$ ) makes current consumption more urgent. This both increases the probability of being constrained for any given initial distribution of $A$ and shifts the distribution of $A$ towards lower asset levels. Both effects work to raise $\Gamma$ in the new steady state. This leads to

Proposition 12: $\Gamma$ is decreasing in $\beta$. 
Proof: Theorem 5.3 in Danthine and Donaldson [6] can be applied to show that $\Psi(A, \beta)>\Psi\left(A, B^{\prime}\right)$ for $B^{\prime}>\beta$. From $(9)_{5} A^{*}(B)>A^{*}\left(B^{\prime}\right)$ for $\beta^{\prime}$ $>\beta$. Therefore, $\Gamma(\beta)=\Psi\left(A^{*}(\beta), \beta\right)>\Psi\left(A(B), \beta^{i}\right)>\Psi\left(A^{*} *\left(\beta^{\prime}, \beta^{\prime}\right)=\Gamma\left(\beta^{\prime}\right)\right.$.

III. Consumption With and Without a Borrowing Restriction

Unconstrained consumers, those with $A \geq A^{*}$, appear to be choosing consumption in a manner consistent with the standard form of the lifecycle, permanent income hypothesis. For them, the first order Euler equations are satisfied with equality. This does not imply that unconstrained consumers, in a wealth-in-advance world, behave identically to consumers in a world where borrowing against future income is possible. In this section, the optimal consumption function derived in section $I$, $c(A)$, and the stationary distribution of $a, \psi *(A)$, will be compared to the outcomes which would arise if borrowing were allowed.

Schechtman and Escudero [1977] provide some results which are relevant for a comparison of optimal consumption with and without a borrowing constraint. Let $c^{\prime}(A)$ be the optimal consumption function of a consumer with spendable resources A who maximizes (1) subject to (3) and the solvency condition $\lim _{t \rightarrow \infty} \beta^{t} A^{t}=0$. Then Lemma 3.6 in Schechtman and Escudero [1977, p. 160] implies that

Proposition 13: $c(A) \leq c^{\prime}(A)$ for all A. 
At each level of $A$, a consumer in a wealth-in-advance economy consumes no more than a similar consumer not faced with the constraint (2). Because consumers facing borrowing restrictions are unable to borrow to maintain consumption in the face of a low realization of transitory income, they will tend to consume less, as a function of $A$, for two reasons. First, if $A<A^{*}$, they are directly constrained by (2) and are forced to consume less than they desire. Second, they will tend to consume less even when unconstrained in order to accumulate wealth as a means of insuring against low realizations of transitory income. This results in a distribution of $A$ that is to the right of that which would arise in a stationary state in the absence of (2). This is proven in

Proposition 14: $\Psi *(A) \leq \Psi^{\prime}(A)$ where $\Psi^{\prime}$ is the stationary distribution of $A$ in the absence of (2).

\section{Proof: Define}

$$
\begin{aligned}
P \Psi & =\int S\left(A^{\prime}-A+c(A)-y\right) d \Psi(A) \\
P^{\prime} \Psi & =\int S\left(A^{\prime}-A+c^{\prime}(A)-y\right) d \Psi(A)
\end{aligned}
$$

By definition, $P \Psi *=\psi^{*}$, and $P^{\prime} \Psi^{\prime}=\Psi^{\prime}$. In addition, $\lim _{i \rightarrow \infty} \mathrm{P}^{i} \Psi=\Psi *, \lim _{i \rightarrow \infty}$ $\mathrm{P}^{\prime i} \Psi=\Psi^{\prime}$ for any initial distribution $\Psi$. From Proposition 13,

$$
A^{\prime}-A+C(A)-y \leq A^{\prime}-A+C^{\prime}(A)-y
$$

for all A. Since $S($ ) is nondecreasing,

$$
S\left(A^{\prime}-A+c(A)-y\right) \leq S\left(A^{\prime}-A+c^{\prime}(A)-y\right) \text {. }
$$

Therefore,

$$
\Psi \cdot x=\int S\left(A^{\prime}-A+c(A)-y\right) d \Psi * \leq S\left(A^{\prime}-A+c^{\prime}(A)-y\right) d \Psi * P^{\prime} \Psi *
$$

Since the operator $\mathrm{P}^{\prime}$ is sign preserving, 
for all A.

$$
\Psi_{*} \leq P^{\prime} \Psi_{*} \leq P^{\prime}\left(P^{\prime} \Psi^{*}\right) \leq \lim _{i \rightarrow \infty} P^{\prime} i_{\Psi^{\prime} *}=\Psi^{\prime}
$$

IV. Aggregate Consumption With a Common Income Shock

It order to derive the stationary distribution of assets, it was necessary to suppress the common income shock, $u$, which had originally been introduced in section $I$. However, in order to analyze how aggregate consumption responds to transitory fluctuations in aggregate income, it is necessary to reintroduce $u$. This implies, however, that the distribution of spendable resources across the population will vary over time as a function of the realizations of $u$.

Suppose $\Psi_{t}\left(A^{\prime \prime}\right)$ is the fraction of consumers with spendable resources less than or equal to $A^{\prime \prime}$ at time $t$. The fraction with resources less than or equal to $A^{\prime \prime}$ at. time $t+1, \Psi_{t+1}\left(A^{\prime \prime}\right)$, is given by

$$
\Psi_{t+1}\left(A^{\prime \prime}\right)=\int S\left[A^{\prime \prime}-A-u_{t+1}-y+c(A)\right] d \Psi_{t}(A)
$$

Thus, $\Psi_{t+1}()$ depends on the actual realization of the aggregate income shock at time $t+1$. Since $S()$ is nondecreasing, a higher $u_{t+1}$ shifts the entire distribution of $A_{t+1}$ to the right: $\Psi_{t+1}(A)$ is nondecreasing in $u_{t+1}$.

Since the fraction of constrained consumers is equal to the fraction with spendable resources less than $A^{*}$, I will now vary in response to transitory aggregate income shocks as such shocks affect the distribution of $A$. It is necessary, then, to add a time subscript to $\Gamma: \Gamma_{t}=$ 
$\Psi_{t}(A *)$. From the definition of $A *$ in equation (9), it is clear that $A^{*}$ depends on the probability distribution of the common shock (since $\phi^{\prime}=$ $\left.\varepsilon^{\prime}+u^{\prime}\right)$, but $A^{*}$ is independent of the current realization of $u$. Thus, the period $t$ realization of $u$ affects $\Gamma_{t}$ only through its effect on $\Psi_{t}$, the distribution of $A^{*}$ across consumers.

Proposition 15: The fraction of constrained consumers is a nonincreasing function of the contemporaneous aggregate income shock.

Proof: Since $\mathrm{S}($ ) is a nondecreasing cumulative distribution function, equation (14) implies

$$
\begin{aligned}
\partial \Gamma_{t} / \partial u_{t} & =\partial \Psi_{t}(A \div) / \partial u_{t} \\
& =-\int S^{\prime}\left[A \div-u_{t}-A-y-c(A)\right] d \Psi_{t-1}(A) \\
& \leq 0
\end{aligned}
$$

Not surprisingly, a positive transitory income shock that is common to all consumers increases the level of spendable resources available to each consumer and thereby reduces the fraction of consumers who find the borrowing restriction to be binding.

Even though the shocks are i.i.d., they induce a pattern of serial correlation in $\Gamma_{t}$. For example, a positive $u_{t}$ reduces $\Gamma_{t}$ and shifts $\Psi_{t+1}$ to the right, relative to the outcomes which would result if aggregate transitory income were zero. The shift in $\Psi_{t+1}$ implies a fall in $\Psi_{t+1}(A \div)=\Gamma_{t+1}$. A positive income shock, because it is partially 
saved, leaves consumers with more assets in the next period. This reduces the probability an individual will become constrained, and, in the aggregate the fraction actually constrained falls.

Proposition 16: $\Gamma_{t+1}$ is nonincreasing in $u_{t}$.

Proof: Integrating (14) by parts yields

$$
\Gamma_{t+1}=S[A *-\bar{A}-y+c(\bar{A})]+\int S^{\prime}\left[A^{*}-A-y+c(A)\right]\left[1-c^{\prime}(A)\right] \Psi_{t}(A)
$$

where $\vec{A}$ is the minimum $A$ such that $\Psi_{t}(\bar{A})=1$. Differentiating with respect to $u_{t}$,

$$
\partial \Gamma_{t+1} / \partial u_{t}=J S^{\prime}[A *-A-y+c(A)]\left[1-c^{\prime}(A)\right] \partial \Psi_{t} / \partial u_{t} \leq 0
$$

since $\partial \Psi_{t} / \partial u_{t} \leq 0$

Heller and Starr [1979] show that individual consumers facing a binding liquidity constraint exhibit excess sensitivity to transitory income. The empirical evidence cited in the introduction suggested that aggregate consumption displays such excess sensitivity. Aggregate per capita consumption, $\mathrm{C}_{t}$, is given by

$$
\begin{aligned}
C_{t} & =f_{\underline{A}}^{\bar{A}} c(A) d \Psi_{t}(A) \\
& =J_{\underline{A}}^{A *} A d \Psi_{t}(A)+J_{A^{*}}^{\bar{A}} c(A) d \Psi_{t}(A)
\end{aligned}
$$

where $\underline{A} \geq 0$ is defined such that $\Psi_{t}(\underline{A})=0$. The contribution to $C_{t}$ of the constrained consumers is equal to $\int_{A}^{A *} A_{t}^{A}(A)$, while the unconstrained contribute $\bar{f}_{A^{*}}^{\bar{A}} c(A) d \Psi_{t}(A)$. All consumers with $A<A *$ are con- 
strained. However, since the realizations of transitory income are partially individual specific, not all consumers who begin the period with equal values of $w$ are constrained (unless $\left.w<w^{*}+\right)^{\prime}$ ). In general, the fraction of all consumers with wealth $w$ who become constrained is $F\left(\phi^{*}\left(w, A^{*}\right)\right)=S\left(\phi^{*}\left(w, A^{*}\right)-u\right)$. The marginal propensity to consume out of wealth is equal to one for the constrained group. The second term in (15) is the consumption of those consumers whose initial wealth plus current income exceeds $A^{*}$. From Proposition 3, such individuals will not be constrained during the current period.

To assess the excess sensitivity of consumption in the presence of borrowing restrictions, consider two individuals, $i$ and $j$, who begin the period with the same level of wealth: $w_{i}=w_{j}$. Suppose the transitory income realizations are such that $w_{i}+y+\phi_{i}<A^{*}<w_{j}+y+\phi_{j}$, so that $i$ is constrained while $j$ is not. Since $c^{\prime}(A)<1$ for all $A \geq A^{*}$, while $c^{\prime}(A)$ $=1$ for $A<A^{*}$, individual $i$ clearly responds more to a small variation in $\phi$ than does $j$. In addition, the binding wealth constraint will make $i$ less sensitivity to variations in future permanent income. (See Heller and Starr [1979].) The presence of constrained consumers will make aggregate consumption more sensitive to current transitory income and less sensitive to future expected income.

From (15), the aggregate marginal propensity to consume out of current aggregate transitory income can be written as

$$
\begin{aligned}
\partial C_{t} / \partial u_{t} & =\Psi_{t}\left(A^{*}\right)+\delta_{A *}^{\bar{A}} C_{A}(A) d \Psi_{t}(A) \\
& =\Gamma_{t}+\int_{A *}^{\bar{A}} C_{A}(A) d \Psi_{t}(A) .
\end{aligned}
$$


The marginal propensity to consume out of transitory income depends directly on the fraction of consumers facing a binding borrowing restriction. Since income shocks have all been assumed to be i.i.d., one might expect the second term in (16) to be close to zero. ${ }^{9}$ Then the aggregate marginal propensity to consume out of transitory income is simply a measure of the fraction of consumers who are constrained and is not a measure of the slope of any representative consumer's optimal consumption function.

Equation (16) is an intuitively obvious result: if aggregate consumption is the sum of consumption by liquidity constrained households and consumption by unconstrained households, the aggregate marginal propensity to consume out of transitory income is an average of one and a small positive number, with weights dependent on the fraction of all households who actually are constrained. The second term in (16) is not quite 1 - $\Gamma$ times a constant since unconstrained households have differing levels of wealth and marginal propensities to consume out of transitory income. The preceding analysis, however, suggests that it is not legitimate to model aggregate consumption as an average of the consumption of a representative constrained household and the consumption of a representative unconstrained household with fixed weights. The weight in such an average is itself a function of aggregate transitory income. $\Gamma$ falls in response to positive transitory income and rises in response to negative transitory income. Since the aggregate marginal propensity to consume is an increasing function of $\Gamma$, it will be less than the value that would be implied by the use of a fixed, cyclical average, value for I. 
V. Conclusions

A number of recent empirical studies have re-evaluated the permanent income-life cycle model of consumption using the insights provided by the assumption of rational expectations. These studies, using both cross-sectional panel and time series data from the U.S., generally reject the implications of the standard formulation of the optimal consumption choice problem. Instead, the data seems to be consistent with the presence of some consumers who face binding borrowing restrictions. The purpose of this paper has been to construct a simple model with income uncertainty in which, each period, some fraction of all consumers do face a binding constraint which limits their current consumption. Even though all consumers are prohibited from borrowing against future income, the behavior of some consumers appears consistent with the life-cycle, permanent income hypothesis. Aggregate consumption is an average of the consumption of these two groups. The model would seem to be consistent with the empirical results obtained by Hall and Mishkin [1982], Hayashi [1982], and Flavin [1984].

Allowing for a common, transitory income shock, it was shown that the aggregate marginal propensity to consume is directly related to the fraction of all consumers who are constrained. Since this fraction was shown to exhibit positive serial correlation in response to i.i.d. income shocks, consumption will be correlated will both current and lagged transitory income.

The analysis has been predicated on the assumption that individuals are unable to borrow against their future endowments. This restriction 
on borrowing is designed to capture the intuitive notion that individuals are limited in their ability to borrow against future labor income. The assumption that no borrowing is possible is made to contrast sharply with the standard life-cycle formulation which allows consumers, if they so desire, to divorce consumption completely from the time pattern of income. While not crucial for present purposes, for other issues it may be important to model explicitly the underlying factors which make it difficult for individuals to issue unsecured liabilities against their future labor income. For example, if permanent income is individual specific and unobservable, credit rationing may arise along the lines analyzed by Stiglitz and Weiss [1981]. 


\section{FOOTNOTES}

1. See also Bernanke [1985]. Flavin [1984] concludes that deviations from the predictions of the permanent income hypothesis are due to the presence of liquidity constraints and are not the result of myopic behavior on the part of consumers.

2. Bernanke [1984], however, finds he cannot reject the permanent income hypothesis in a model of consumer auto purchases.

3. See also Pissaridis [1978] and Dolde [1978]. Koskela and Viren [1984] treat the probability of being constrained as exogenous.

4. See Tables 1-10 in "Survey of Consumer Finances, 1983", Federal Reserve Bulletin September 1984.

5. Bewley [1977] allows for preference uncertainty as well.

6. Since they allow for assets to earn interest, they actually test the hypothes is that $(1+r) B E u_{c}\left(c^{\prime}\right)=u_{c}(c)$. See also Ferson and Merrick
$[1985]$.

7. $\phi^{*}\left(w, A^{*}\right)$ depends on both $w$ and $A^{*}$, but only $w$ is individual specific.

8. If $\mu>0$, then $\mu_{t}=u_{c}\left(w_{t}+y+\phi_{t}\right)-\beta V$.

9. This is because $c_{A}(A)$ would be close to zero. 


\section{REFERENCES}

1. Berge, Claude, Topological Spaces Oliver and Boyd, 1963.

2. Bernanke, Ben, "Permanent Income, Liquidity, and Expenditures on Automobiles: Evidence from Panel Data", Quarterly Journal of Economics 99 (August 1984), 587-614.

3. Bernanke, Ben, "Adjustment Costs; Durables and Aggregate Consumption", Journal of Monetary Economics 15 (January 1985), 41-68.

4. Bewley, Truman, "The Permanent Income Hypothesis: A Theoretical Formulation", Journal of Economic Theory 16 (December 1977), $252-292$.

5. Blackwel1, David, "Discounted Dynamic Programming", Annals of Mathematical Statistics, 36, (1965), 226-235.

6. Clarida, Richard H., "Optimal Spending and Money Holdings in the Presence of Liquidity Constraints and Random Income Fluctuations", April, 1984.

7. Danthine, Jean-Pierre and John B. Donaldson, "Stochastic Properties of Fast vs. Slow Growing Economies", Econometric 49 (1981), 1007-1033.

8. Dolde, Walter, "Capital Markets and the Short Run Behavior of Life Cycle Savers", Journal of Finance 33 (May 1978), 413-428.

9. Ferson, Wayne E. and John J. Merrick, Jr., "Nonstationarity and Stage-of-the-Business-Cycle Effects in Consumption-Based Asset Pricing Relations", Graduate School of Business Administration, New York University, Working Paper No. 336 (January 1985).

10. Flavin, Marjorie, "Excess Sensitivity of Consumption to Current Income: Liquidity Constraints or Myopia?", NBER Working Paper No. 1341, May 1984.

11. Flemming, J. S., "The Consumption Function When Capital Markets are Imperfect: The Permanent Income Hypothes is Reconsidered", Oxford Economic Papers 25 (July 1973), 160-172.

12. Foley, Duncan K. and Martin F. Hellwig, "Asset Management with Trading Uncertainty", Review of Economic Studies 42 (July 1975), $327-346$. 
13. Goldman, Steven M., "Flexibility and the Demand for Money", Journal of Economic Theory 9, (1974), 203-222.

14. Hall, Robert E. and Frederic S. Mishkin; "The Sensitivity of Consumption to Transitory Income: Estimates from Panel Data on Households", Econometrica 50, (1982), 461-481.

15. Hamermesh, Daniel S., "Social Insurance and Consumption: An Empirical Inquiry", American Economic Review 72 (1982), 101-113.

16. Hansen, Lars Peter and Kenneth J. Singleton, "Stochastic Consumption, Risk Aversion, and the Temporal Behavior of Asset Returns", Journal of Political Economy 91 (1983), 249-266.

17. Hayashi, Fumio, "The Permanent Income Hypothesis: Estimation and Testing by Instrumental Variables", Journal of Political Economy 90 (1982), 895-916.

18. Heller, Walter Perrin and Ross Starr, "Capital Market Imperfections, the Consumption Function, and the Effectiveness of Fiscal Policy", Quarterly Journal of Economics 93 (August 1979), 455-463.

19. King, Mervyn, "The Economics of Saving", NBER Working Paper No. 1247, December 1983.

20. Koskela, Erkki and Matti Viren, "Credit Rationing and Consumer Intertemporal Choice", Oxford Economic Papers 36 (June 1984), 241-247.

21. Kotlikoff, Laurence $J$. and Ariel Pakas, "Looking for the News in the Noise - Additional Implications of Optimal Consumption Choice", NBER Working Paper No. 1492, November 1984.

22. Leland, Hayne E., "Saving and Uncertainty: The Precautionary Demand for Saving", Quarterly Journal of Economics 82 (1968), 465-473.

23. Lucas, Robert E. Jr., "Asset Prices in an Exchange Economy", Econometrica 46 (1978), 1429-1445.

24. Lucas, Robert E. Jr., "Equilibrium in a Pure Currency Economy", in Models of Monetary Economies Federal Reserve Bank of Minneapolis, 1980 .

25. Lucas, Robert E. Jr., "Interest Rates and Currency prices in a Two-Country World", Journal of Monetary Economics 10 (1982), 335-359.

26. Miller, Bruce L., "The Effect on Optimal Consumption of Increased Uncertainty in Labor Income in the Multiperiod Case", Journal of Economic Theory'13 (August 1976), 154-167. 
2. Pissarides, Christopher A., "Liquidity Considerations in the Theory of Consumption", Quarterly Journal of Economics 92 (May 1978), 279-296.

28. Rothschild, Michael and Joseph E. Stiglitz, "Increasing Risk: I, A Definition", Journal of Economic Theory 2 (1970), 225-243.

29. Schechtman, Jack and Vera L. S. Escudero, "Some Results on 'An Income Fluctuation Problem'", Journal of Economic Theory 16 (1977), 151-166.

30. Sibley, David S., "Permanent and Transitory Income Effects in a Model of Optimal Consumption with Wage Income Uncertainty", Journal of Economic Theory 11 (1975), 68-82.

31. Stiglitz, Joseph E. and Andrew Weiss, "Credit Rationing in Markets with Imperfect Information", American Economic Review June 1981, $71,393-410$.

32. Survey of Consuner Finances, 1983, Federal Reserve Bulletin Board of Governors of the Federal Reserve System, September 1984.

33. Svensson, Lars E. O., "Money and Asset Prices in a Cash-in-Advance Economy", mimeo, Dec. 1983.

34. Yaari, Menahem E., "A Iaw of Large Numbers in the Theory of Consumer's Choice Under Uncertainty", Journal of Economic Theory 12 (Apri1 1976), 202-217.

35. Zeldes, Stephen, "Consumption and Liquidity Constraints: An Empirical Investigation", mimeo, July 1984. 